Eval uat $i$ on of I nt erfaci al St rength of BNT Fi I ns Hydr ot her nal I y Deposi ted on Ti t ani um Subst $r$ at es

\begin{tabular}{|l|l|}
\hline 著者 & KUSUKAWA Kazuhi ro, XU Fangchao \\
\hline $\begin{array}{l}\mathrm{j} \text { our nal or } \\
\text { publ i cat i on ti l l e }\end{array}$ & I nt er nat i onal j our nal of moder n physi cs. B \\
\hline vol une & 24 \\
\hline nunber & $15-16$ \\
\hline page $\mathrm{r}$ ange & $3053-3058$ \\
\hline year & $2010-06$ \\
\hline URL & ht t p: //hdl . handl e. net /10173/772 \\
\hline
\end{tabular}




\title{
EVALUATION OF INTERFACIAL STRENGTH OF BNT FILMS HYDROTHERMALLY DEPOSITED ON TITANIUM SUBSTRATES
}

\author{
Kazuhiro KUSUKAWA \\ Department of Intelligent Mechanical Systems Engineering, Kochi University of Technology, \\ Tosayamada-cho, Kochi, 782-8502, Japan \\ kusukawa.kazuhiro@kochi-tech.ac.jp \\ Fangchao XU \\ Department of Intelligent Mechanical Systems Engineering, Kochi University of Technology, \\ Tosayamada-cho, Kochi, 782-8502, Japan \\ 108003p@gs.kochi-tech.ac.jp

\begin{abstract}
Lead-free piezoelectric $\left(\mathrm{Bi}_{1 / 2} \mathrm{Na}_{1 / 2}\right) \mathrm{TiO}_{3}$ (abbreviated as BNT) films were deposited on $0.2 \mathrm{~mm}$ thick pure titanium(Ti) substrates by a hydrothermal method. Scratch tests and Vickers indentation tests were performed to quantitatively assess the adhesion strength between BNT films and Ti substrates. Some of Ti substrates were pretreated by chemical polish and mechanical polish respectively prior to BNT film deposition with a view of investigating the effects of substrate surface pretreatments on the adhesion of BNT films. In the scratch test, the critical force was determined from the variations of the tangential force and the acoustic emission (AE) signals with the normal force. The scratch test results revealed that the chemical polish pretreatment effectively improved the adhesion of BNT films. In addition, the critical substrate strain inducing the adhesion failure of BNT film has been investigated by the Vickers indentation test combined with finite element analysis (FEM).
\end{abstract}

Keywords: Adhesion, BNT film; Hydrothermal method; Indentation; Scratch.

\section{Introduction}

Piezoelectric materials have wide applications in microelectronic and micromechanical systems due to their direct and inverse piezoelectric effects. BNT film is one of lead-free piezoelectric films which are attractive in potential applications owing to their developing the miniaturization of sensor and the intelligentization of system. ${ }^{1}$ Almost all deposited film applications require that the films adhere sufficiently to the substrates. Therefore, the interfacial adhesion strength between a film and a substrate is often the predominant factor and chief target in determining the performance and reliability of the film/substrate system. ${ }^{2,3}$ Quantitative assessment of the adhesion is quite important to understand the film characteristics and develop high quality films. Common methods to evaluate the adhesion of film include pull-off test, scratch test, and indentation test. ${ }^{4,5}{ }^{6}$ The pull-off test is accurate and quantitative if the pulling force can be calibrated well normal to the sample surface. The main restriction with this method is that the tested critical force is limited by the strength of the adhesive, normally weaker than $90 \mathrm{MPa}$. Thus, the adhesive usually fails prior to the films. ${ }^{4}$ 
In the present study, scratch tests combined with SEM observations and Vickers indentation tests combined with finite element analysis were conducted to assess the adhesion of BNT films on Ti substrates.

\section{Materials and Methods}

\subsection{Sample preparation}

BNT films were hydrothermally synthesized on pure titanium substrates $(40 \times 20 \times 0.2 \mathrm{~mm})$. The hydrothermal method used to deposit BNT films has been described elsewhere. ${ }^{7}$ In the hydrothermal synthesis of BNT films, Bismuth nitrate $\left(\mathrm{Bi}\left(\mathrm{NO}_{3}\right)_{3} \cdot 5 \mathrm{H}_{2} \mathrm{O}\right)$, titanium oxide $\left(\mathrm{TiO}_{2}\right)$ and sodium hydroxide $(\mathrm{NaOH})$ were used as starting materials. The details have been given in our previous paper. ${ }^{1}$ BNT films of $6 \sim 8 \mu \mathrm{m}$ thick were obtained using the two-step deposition.

Table 1 shows the surface treatments of $\mathrm{Ti}$ substrates. In the chemical polish pretreatment, the reaction solution was prepared by nitric acid $\left(\mathrm{HNO}_{3}, 34.3 \mathrm{vol} \%\right)$, hydrofluoric acid (HF, 11.4 vol\%) and distilled water. After the pretreatment, the substrates were ultrasonically cleaned in a methanol bath followed by a rinse in distilled water. The surface roughness $R a$ was measured for all the substrates to be deposited using a laser microscope.

\subsection{Scratch test}

Scratch tests were performed on the BNT deposited samples using the self-made scratch tester with a diamond indenter. This system consists of an indenter head, an adjustable stage, a step motor and AE system. Figure 1 shows the indenter head of the scratch tester. This scratch tester employed a sliding conical diamond indenter with apex angle $120^{\circ}$ and spherical tip radius $50 \mu \mathrm{m}$. In the scratch test, the stage was adjusted to a slope with an angle of $3^{\circ}$. The normal load imposed on the sample increased continuously during the scratching test. Scratch tests were carried out at a scratching speed of $3 \mathrm{~mm} / \mathrm{min}$ over about $2 \mathrm{~mm}$ scratch distance. During scratch testing, the signals of normal force, tangential force and acoustic emission were simultaneously recorded. After scratching, the scratch channels were observed by SEM.

Table 1. Surface treatments of Ti substrates prior to the deposition of BNT films.

\begin{tabular}{ll}
\hline Sample & Pretreatment method \\
\hline AR & $\begin{array}{l}\text { As received with calendering } \\
\text { Mechanical polish by a } 240 \text { grit } \\
\text { emery paper }\end{array}$ \\
E1000 & $\begin{array}{l}\text { Mechanical polish by a } 1000 \text { grit } \\
\text { emery paper }\end{array}$ \\
CP & $\begin{array}{l}\text { Chemical polish by pickling in the } \\
\text { prepared solution }\end{array}$ \\
\hline
\end{tabular}

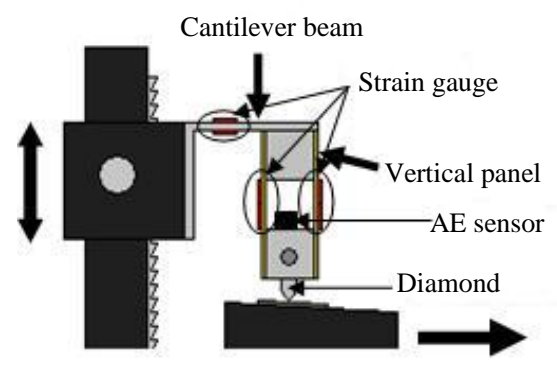

Fig. 1. Schematic diagram of the indenter head of the self-made scratch tester. 


\subsection{Vickers indentation test}

Vickers indentation tests were carried out on CP using a microhardness tester. The indenter tip was a Vickers tip with a pyramidal square base and a 136-degree angle between opposing faces. The indentations were performed under a set of discrete loads $(0.98,2.94,4.9$ and $9.8 \mathrm{~N})$, with a $15 \mathrm{~s}$ hold under the maximum load. After indentation, the morphologies of indentations were observed, and the indentation edge length and the delamination area of BNT film around the indentation were measured using the laser microscope system.

\section{Results and Discussion}

\subsection{Scratch test}

SEM observations of the scratched sample showed that the scratch channels were composed of two stages before and after the diamond indenter reached the film/substrate interface. The first stage, at low normal force, involved the film deformation which didn't cause adhesive failures of BNT film (Fig. 2a and b). In the second stage, the film exfoliations were observed around the scratch channel owing to the deformations of film and substrate (Fig. 2c).

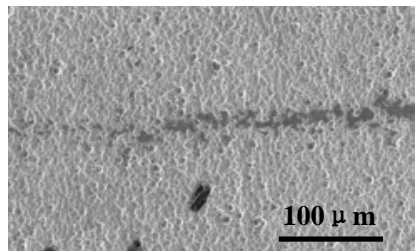

(a) The fore part

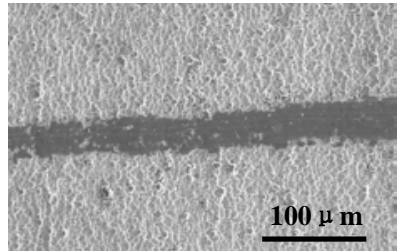

(b) The middle part

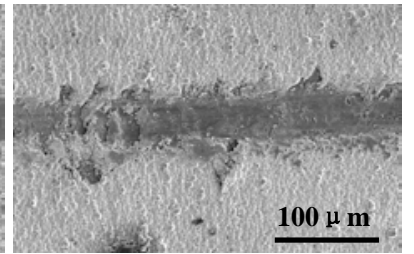

(c) The rear part

Fig. 2. SEM images of the different parts of the scratch channel (E1000)

Scratch direction

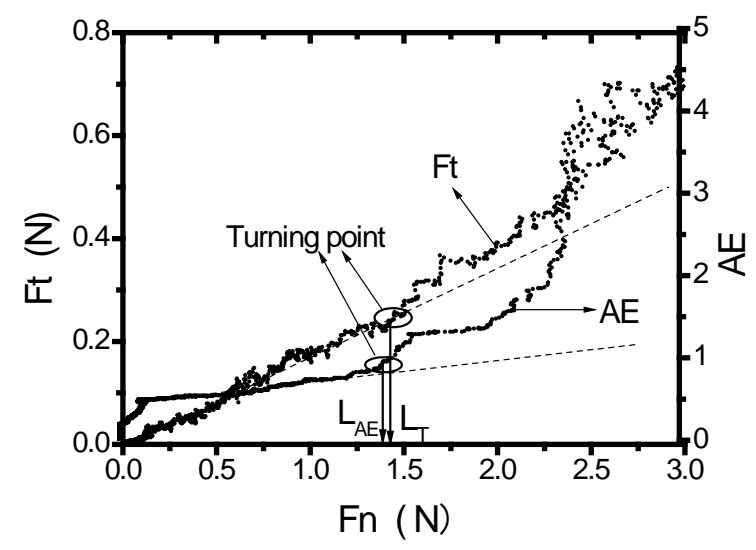

Fig. 3. Variations of the tangential force and AE signal with the normal force (AR). 
Figure 3 shows the variations of the tangential force (Ft) and $\mathrm{AE}$ signal with the normal force (Fn) during the scratch test for AR. As the mechanical properties of the film and substrate are different, there is a turning point in the slope of $\mathrm{Ft} / \mathrm{Fn}$ when the indenter reaches the film/substrate interface. At this turning point, the normal force is regarded as the critical normal force which, if sufficiently large, induces adhesive failure. In this study, the critical normal force was used to assess the adhesion strength of BNT film on its substrate. Figure 3 illustrates the good agreement between the results from tangential force measurements and acoustic emission detection in the determination of critical force.

The critical force obtained by the scratch test for each sample and the surface roughness for each substrate are shown in Fig. 4 and Fig. 5, respectively. It was reported that the increase in the mechanical interlock between the film and the substrate by surface roughening resulted in the improvement of the adhesion of film. ${ }^{8}$ It can be found from the scratch test results (Fig. 4 and Fig. 5) that E240 with the roughest substrate surface is the weakest in the adhesion strength of BNT film in all the tested samples. We can deduce that the better adhesion of film on its substrate is obtained for a substrate of moderate roughness. In other words, the rougher substrate surface doesn't always increase the mechanical interlock between film and substrate, and doesn't always produce the stronger adhesion of film. It can be also seen from Fig. 4 that higher adhesion strengths were obtained for chemically polished samples, which may be attributed to the formation of an interlayer produced by chemical reaction on the substrate surface.

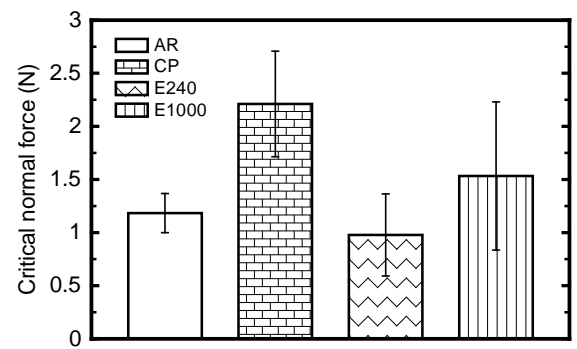

Fig. 4. The critical normal force for various samples.

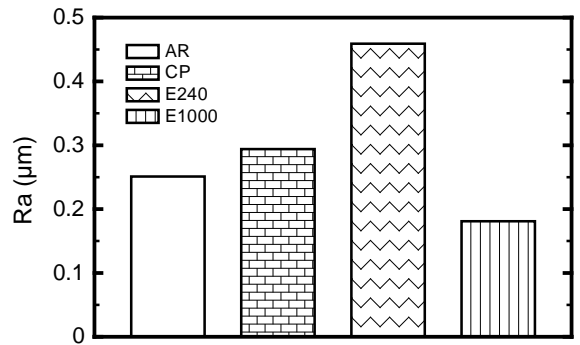

Fig. 5. Surface roughness of various substrates

\subsection{Vickers indentation test}

An indentation in the film deposited substrate may cause the following failure modes: (1) the substrate cracking; (2) the film cracking and localized exfoliation; and (3) the adhesion failure at the film/substrate interface and the film delamination. ${ }^{4}$ In this study, we can firstly rule out the possibility of the first mode because Ti substrate is ductile. In addition, no film cracking was observed at lower indentation load before the generation of film delamination. Therefore, we can rule out the possibility of the second mode. The above results suggest that Vickers indentation induced the adhesion failure at the BNT film/Ti substrate interface, and then caused the film delaminations. This failure type was confirmed as localized convexity on microscopic observations (Fig. 6). Figure 7 shows 
the relationship between the film delamination area and the applied indentation load. The delamination area increases monotonously with increasing the indentation load.

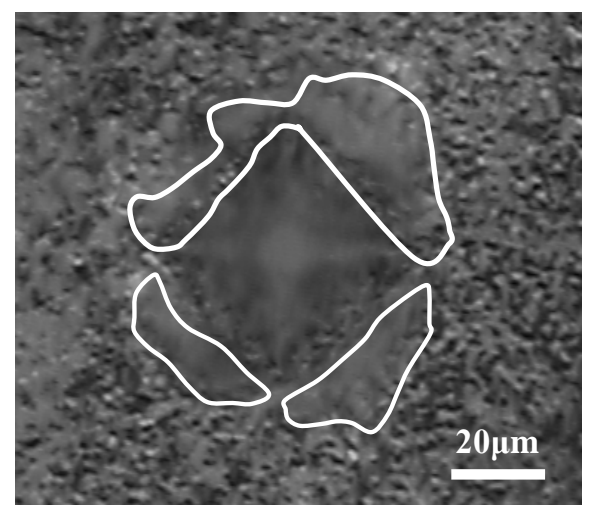

Fig. 6. Micrograph of indentation with 2.94 N.

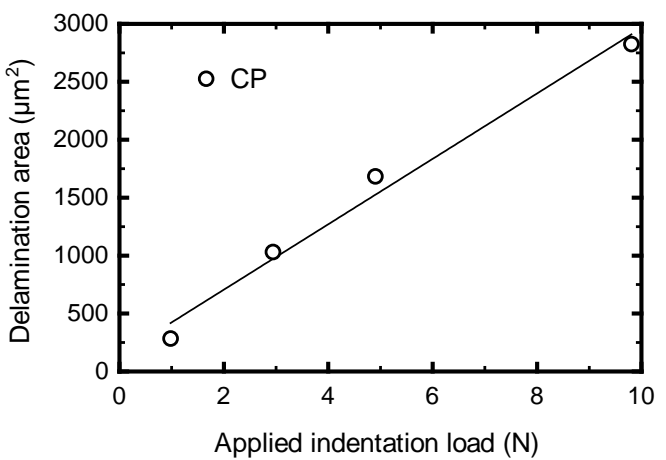

Fig. 7. Variation of the film delamination area with the applied indentation load.

In order to investigate the strain field where film delaminations occurred, threedimensional FEM analysis of Vickers indentation was performed using ANSYS Res. 11.0 software package. The Vickers indenter was assumed rigid, and the model material was treated as a homogeneous, isotropic, rate-independent and non-linear plastic body. Due to the symmetry, one fourth model of the indentation was studied, as shown in Fig. 8. Figure 9 shows the comparison of the experimental and simulative results on the indentation edge length. It indicates that the above FEM model is valid for this analysis.

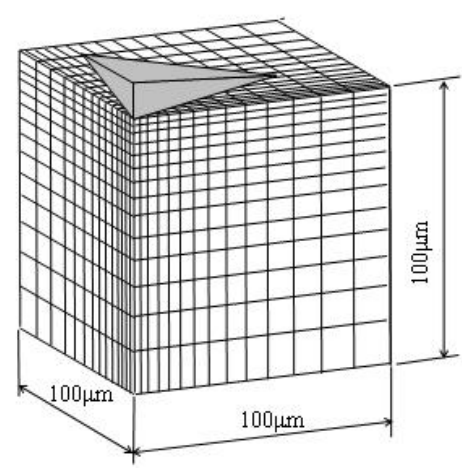

Fig. 8. The three-dimensional mesh model used for the FEM analysis of one fourth of indentation.

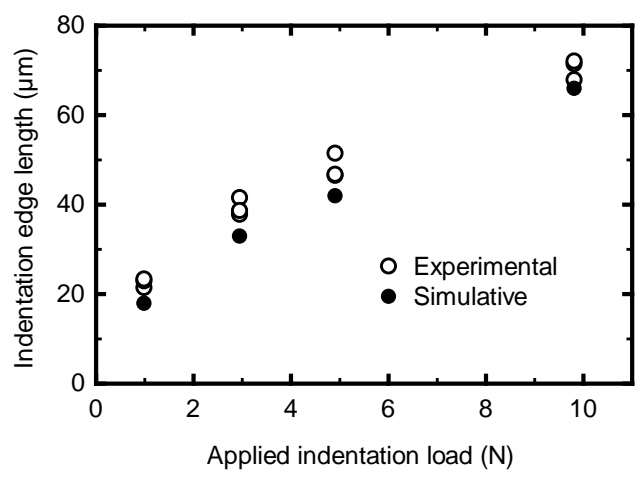

Fig. 9. Variation of the indentation edge length with applied indentation load.

Figure 10 shows the plastic shear strain $\left(\gamma_{x y}\right)$ field on the indentation surface after the 2.94 load indentation. The extent of lines in this drawing shows the area where film 
delaminations occurred. Based on a comprehensive consideration of the same mapping under all the indentation load levels, we can conclude that the critical plastic in-plane strain on the substrate which induces film delaminations is about 0.2 .

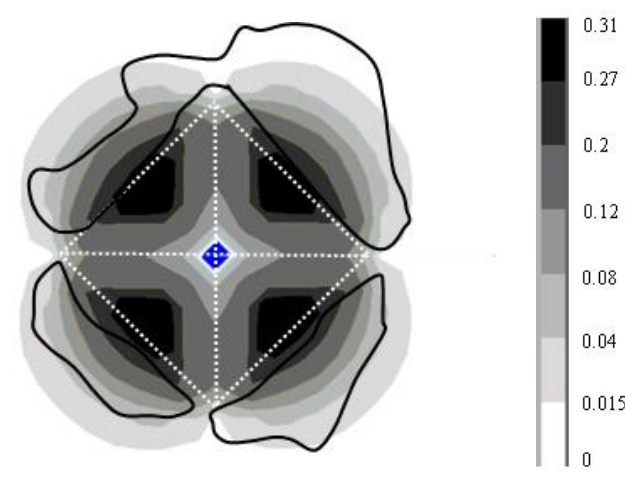

Fig. 10. In-plane plastic shear strain $\gamma_{x y}$ field with $2.94 \mathrm{~N}$ indentation determined in FEM and delaminated area.

\section{Conclusions}

In this study, BNT films were successfully deposited on pure titanium substrates by the hydrothermal method. Scratch tests and Vickers indentation tests were performed to assess the adhesion strength between BNT film and Ti substrate. The main conclusions were summarized as follows:

(1) The scratch test was used to effectively evaluate the adhesion strength between BNT film and Ti substrate by investigating the critical force.

(2) On the effect of surface pretreatment of $\mathrm{Ti}$ substrate, the chemical polish pretreatment produced the best effect, as the critical normal force increased from 1.2 to $2.2 \mathrm{~N}$.

(3) The indentation test results suggest that the film delaminations after the indentation were primarily attributed to the plastic deformation of Ti substrate, and the critical shear strain $\gamma_{x y}$ have been evaluated to be about 0.21 .

\section{References}

1. F. C. Xu and K. Kusukawa, Advanced Materials Research, 47-50, 73 (2008).

2. X .J. Zheng, Y. C. Zhou, J. M. Liu and A. D. Li M, Physics Letters A, 304, 110 (2002).

3. H. Q. Li, X. Cai and Q. L. Cheng, Journal of Materials Science Letters, 20, 2167 (2001).

4. Q. H. Fan, J. Gr'acio, Nasar Ali and E. Pereira, Diamond and Related Materials, 10, 797 (2001).

5. A.A. Volinsky, N.R. Moody and W.W. Gerberich, Acta Materialia, 50, 441 (2002).

6. J. G. Buijnster, P. Shankar and W. J. P. van Enckevort, Diamond and Related Materials, 13, 848 (2004).

7. S. Euphrasie, S. Daviero-Minaud and P. Pernod, Materials Science and Engineering, B104, 180 (2003).

8. N. Ali, G. Cabral, A. B. Lope and J. Gracio, Diamond and Related Materials, 13, 495 (2004) 